\title{
TACIT AND EXPLICIT KNOWLEDGE IN CONSTRUCTION MANAGEMENT
}

\author{
Mark Addis ${ }^{1}$ \\ Faculty of Performance, Media and English, Birmingham City University, Perry Barr, Birmingham, \\ B42 $2 S U, U K$
}

\begin{abstract}
In construction better practice has been sought through the employment of knowledge management. Interest in tacit knowledge has grown due to its importance for raising performance at all organisational levels. Aspects of the limits which tacit knowledge places on knowledge management approaches in construction are considered with the focus being upon broad knowledge management categories rather than the details of particular methods. The distinction between knowing how and knowing that coupled with examination of whether the main mode of knowing is tacit or explicit is used to analyse the relationship between tacit and explicit knowledge in construction. There are significant general theoretical difficulties with incorporating tacit knowledge into the objectivist knowledge management approaches which predominate in construction particularly since methods for converting tacit to explicit knowledge are problematic. Improving performance requires appreciating the limitations of objectivist and practice based knowledge management within the context of construction projects as consideration of performance management measures illustrates.
\end{abstract}

Keywords: information management, measurement, tacit knowledge.

\section{INTRODUCTION}

Performance in the UK construction industry has long been regarded as unsatisfactory (Latham 1994, Egan 1998 and Wolstenholme 2009). Despite a number of reviews and policy initiatives to produce productivity, quality and competitiveness gains the industry has failed to meet improvement targets in a range of areas. A significant way in which better practice has been sought is through the employment of knowledge management due to increasing recognition that it can bring about competitive advantage through innovation and improved performance (Egbu 2004). Knowledge management is utilised to facilitate a structured approach to learning from construction projects and to find ways to share and reuse this knowledge. For knowledge management to deliver the greatest benefits an appropriate method must be used in an appropriate way so recognising theoretical limitations which are practically important is essential.

The relatively low-tech labour intensive nature of construction means that people are the most valuable asset an organisation has. Despite this the worth of the knowledge and skills which people have continues to be under appreciated. As Egan (1998 p.14) put it:

\footnotetext{
${ }^{1}$ mark.addis@bcu.ac.uk
} 
“... much of construction does not yet recognise that its people are its greatest asset and treat them as such. Too much talent is simply wasted, particularly through failure to recognise the significant contribution ...".

Interest in tacit knowledge in construction has grown in the last few decades as its importance for raising performance and competitiveness at all organisational levels has become apparent. Its value for construction is demonstrated by the extent to which the industry relies on skills and the capacity to bring different ones together effectively (Druker and White 1996).

This paper particularly focuses on aspects of the limits which tacit knowledge places on knowledge management approaches in construction. As result of this the concern is largely with broad knowledge management categories rather than the details of particular methods. It is argued that the very nature of tacit knowledge means that there are significant general theoretical problems with incorporating into it the objectivist knowledge management approaches which predominate in construction. These theoretical problems impose substantial practical constraints upon the incorporation of tacit knowledge which cannot be dealt with by improved work flow documentation, better use of technology, and other similar strategies. Fully appreciating this difficulty involves recognising that theoretical representations of knowledge management can serve both descriptive and normative functions. Such representations can be normative in that a representation acts as a standard for judging facets of practice. Insufficient understanding of how and why variance between normative representations of practice and practice itself occurs can be a barrier to its improvement. Attempts to make knowledge in practice conform to inappropriate theoretical representations of knowledge management may well confer no benefit at all.

\section{OBJECTIVIST KNOWLEDGE MANAGEMENT}

Types of knowledge management can be broadly classified as either objectivist or practice based (Burrell and Morgan 1979 and Schultze and Stabell 2004). Objectivist knowledge management predominates in construction with most improvement initiatives seeking to enhance practitioner knowledge through this approach (Anumba et al. 2005 and Tan et. al 2010). This type of knowledge management belongs to the category of cognitive models which are based on the value of using and develop knowledge (Kakabadse et al. 2003). In objectivist knowledge management knowledge is primarily regarded as a cognitive entity rather than comprising part of a social practice (Cook and Brown 1999). Knowledge is deemed to be objective facts which are free from individual subjectivity with much organisational knowledge typically being of this character. It is possible to separate knowledge from the individuals or groups which possess it. Analysing knowledge focuses upon the identification of component elements as this is a prerequisite for the codification of knowledge. The individual elements of knowledge identified in analysis have at the very least an independent meaning. The process of managing knowledge is regarded as the extraction of knowledge from individuals or groups so that it can be codified thereby enabling control and application thereby raising organisational performance.

Knowledge is represented, collected and stored in a systematic, generalised and codified way (Hislop 2009). Through this knowledge generated during the course of construction projects is captured, shared and reused with the newly assimilated knowledge being codified and used to update artefacts such as check lists and databases. The central role which codification and control has in objectivist 
knowledge management naturally leads to a strong emphasis upon the importance of logical rationality particularly with regard to evaluation and causation. Knowledge is embedded into rules which have a logical causative rationale and which the practitioner is then meant to follow. There is an emphasis on predictability and a diminished role for the management of uncertainty. The increased focus on the role of information technology in construction over the last decade or so has resulted in objectivist knowledge management concentrating heavily upon the delivery of technological solutions (Anumba et al. 2005 and Tan 2010).

\section{TACIT AND EXPLICIT KNOWLEDGE}

The nature of tacit knowledge in construction imposes limitations on the effectiveness of objectivist knowledge management. It has difficulty dealing with tacit knowledge and this matters because explicit knowledge is only a small part of relevant construction practice knowledge. In order to appreciate the problem it is important to recognise that tacit knowledge is not problematic in itself, as such knowledge clearly exists, but precisely articulating the nature of tacit knowledge is. This is because tacit knowledge is knowledge that an individual has but which cannot be articulated (Polanyi 1958 and 1966). Definitions of tacit knowledge in the literature vary in their details but there is general agreement that tacit knowledge is personal know how primarily acquired through education, training and experience. As a result of this tacit knowledge is a complex content dependent notion which covers a wide range of diverse cases with examples of it including intuition and interpersonal skills. There is no common property or attribute which all cases of tacit knowledge share and its coherence is of a family resemblance kind (Wittgenstein 2009). In construction instances of tacit knowledge could range from the ability to plaster to interaction with the supply chain (Egbu and Robinson 2005). A complication in the literature on tacit knowledge is that it is expressed as both being knowledge which cannot be explicated (Polanyi 1958 and 1966) and knowledge which is not explicated (Collins 2010). The difference between 'cannot' and 'is' is both theoretically important and practically relevant since tacit knowledge which could be explicated but has not been is the kind which could potentially be codified. In what follows the concern will be with tacit knowledge which cannot be explicated.

Construction knowledge is multidimensional and multivalent involving propositional, experiential, performative and epistemological kinds all of which engage with truth in different ways. These sorts of knowledge act together and it is only a small amount of mainly the explicit kind that can be easily codified and represented (Mingers 2008) with one estimate claiming that $80 \%$ of useful construction knowledge is tacit (Sheehan et al. 2005). The extensive reliance on tacit knowledge is partly a result of much construction knowledge being in minds of those working on a project, an absence of documentation about the motivations for decisions, and people leaving the project for another once construction is completed. Research on objectivist knowledge management in construction recognises that explicit knowledge only identifies a limited aspect of the thinking and acting in practice. It attempts to account for the heavy dependence on tacit knowledge in construction practice by codification methods for converting tacit to explicit knowledge. For example, Anumba et al. (2005) suggest that experiences of construction professionals are based on a balance between explicit and tacit knowledge in different phases of a project and they are interchangeable by different codification methods. The principal codification method is the SECI conversion model which involves socialisation, externalisation, combination and internalisation (Nonaka and Takeuchi 1995 and Nonaka et al. 2000). 
However, as Baumard (1999 p.4) observes this method contains an unavoidable paradox as knowledge which cannot be codified is analysed by a codification method.

The problem of the substantial amount of tacit knowledge in construction cannot be wholly satisfactorily addressed by the methods used for codifying tacit knowledge so it can be converted into explicit knowledge. The significant general theoretical problems which these conversion methods have can be demonstrated by considering how tacit and explicit knowledge relate to the distinction between knowing how and knowing that. Ryle (1946 and 1949) influentially argued that the kinds of knowledge involved in knowing that and knowing how are distinct. (For a long time this view was widely accepted and despite some criticism from analytic philosophers in the last decade or so it is still considered by many to be a viable position (Winch 2010).) Knowing that is propositional knowledge whilst knowing how is non-propositional knowledge. For example, knowledge of the chemical composition of plaster is knowledge that but the ability to plaster is knowledge how. The difference between these types of knowledge is less apparent in English than French or German both of which have distinct verbs for these kinds of knowledge.

Ryle's (1946 and 1949) central argument for claiming that knowing how is irreducible to knowing that appeals to regress. He claimed that if knowing how is a kind of knowing that then to engage in action a person would have to contemplate a proposition (because knowing that is propositional knowledge). However, the contemplation of a proposition is itself an action which would have to be accompanied by the separate and distinct contemplation of a proposition. It follows that there would be a never ending regress of contemplating propositions with the consequence that knowing how could never be manifested. This argument provides justification for taking knowledge to consist of knowing how and knowing that where these are distinct kinds of knowledge. There has been criticism of Ryle's view that the two kinds of knowledge operate in wholly distinct ways on the grounds that a satisfactory account of expertise in an occupational capacity should explain how these kinds of knowledge interact. The difficulty with Ryle's view is that a great deal of knowing how requires the possession of knowledge that such as in the case of the ability to plaster partly being dependent on knowing facts about plastering. This objection can be fairly easy dealt with in a way which leaves Ryle's main claims intact by modifying his account to take proper account of the interaction between knowing how and knowing that in the performance and justification of action (Winch 2009). It is worth observing these theoretical arguments in favour of expertise requiring an integration of knowing how and knowing that are corroborated by a chunking model of expertise from psychology. This model is strongly supported by experimental evidence and provides a powerful explanation of learning and expert behaviour through the idea that expertise gradually builds up through the incremental and implicit learning of both knowing how and knowing that (Gobet 2005).

Given that Ryle's distinction between knowing how and knowing that is sustainable it is time to consider how tacit and explicit knowledge relate to knowing how and knowing that. Explicit knowledge is straightforwardly equivalent to knowing that. However, characterising the relationship between knowing how and tacit knowledge is more difficult since the equivalence does not go both ways. Not all knowing how is tacit knowledge because there is some knowing how which can be explicated, such as manual instructions explaining how to set cutting blades. Since tacit knowledge is knowledge that an individual has but which cannot be articulated it follows that it cannot be knowing that and so must be knowing how. Having established that tacit 
knowledge is knowing how an application of Ryle's regress argument that knowing how is irreducible to knowing that can be used to show that the SECI model conversion of tacit to explicit knowledge is problematic in principle. For codification to be possible the SECI model has to be able to decontextualise knowledge including those elements of it which cannot be individually identified. If knowing how cannot be reduced to knowing that and tacit knowledge is knowing how then it follows that tacit knowledge cannot be reduced to knowing that. If such a reduction is not possible then the decontextualisation involved in codification is not possible.

\section{PRACTICE BASED KNOWLEDGE MANAGEMENT}

In objectivist knowledge management explicit knowledge is taken to be the main mode of knowledge and tacit knowledge must be explained in reference to it. The problem that tacit knowledge which cannot be codified poses for it is a direct consequence of regarding explicit knowledge as the primary mode. In contrast to the objectivist knowledge management perspective many in practice based knowledge management, psychology and the sociology of knowledge claim that tacit knowledge is the main mode of knowledge and explicit knowledge must be explained in reference to it. Explicit knowledge must rely on being tacitly understood and applied with the consequence that all knowledge is either tacit or rooted in tacit knowledge. An entirely explicit knowledge is inconceivable (Polayni 1958 and 1966). Tsoukas (2003) has developed Polayni's ideas to claim that even the most explicit knowledge is only practically applicable via the exercise of skill and judgement. He employs the distinction Polanyi makes between focal and subsidiary awareness to criticise the SECI model on the grounds that it does not actually convert tacit to explicit knowledge. Tsoukas argues that the conversion procedure extracts the know that aspects of the knowledge (that is focal awareness) without accessing the whole purposeful meaning of an activity (that is subsidiary awareness). He maintains that reflection after an activity merely extracts what can be articulated linguistically and subsidiary awareness can never be expressed explicitly. This is because attempts to articulate the subsidiary awareness of a particular activity would mean that an individual would no longer be engaged in that activity but would instead be engaged in the activity of thinking about that particular activity. Arguments like those of Polanyi and Tsoukas present are complex and controversial but they provide grounds for examining the status of the claim that explicit knowledge is the main mode of knowledge. In objectivist knowledge management it might be thought to be serving a descriptive function but the criticisms of it just noted suggest that its normative function could well be at least as significant.

The importance of irreducible tacit knowledge ensures that types of practice based knowledge management have a valuable role in construction. An approach which usefully accommodates the complex context dependent nature of tacit knowledge is sensemaking. From a sensemaking perspective practice is about observation and inquiry to understand situations by locating them within previous experiences. Sensemaking involves current positions determining what is sought, the past framing what can be seen in a situation, cues which align situations with previous experiences and plausible construal within a social situation taking preference over accuracy. Interactions result in greater understanding which reshapes the sense that is being made of the situation (Weick 1995 and 2001). Given these ideas about sensemaking expertise can be regarded as drawing on situated experience where actions are negotiated from norms of knowledge, social and organisational positions and perceptions of risk (Lave and Wenger 1991) along with involving the ability to engage 
in the right kind of deliberation and actions in situations where there is incomplete information through an appropriate appreciation of context (Boyd 2006). What this and the preceding discussion suggest is that in construction objectivist and practice based knowledge management should be regarded as complementary rather than competitive. Instead of attempting to demonstrate, as quite commonly has been done, that one approach is better than the other emphasis should be placed upon recognising the limitations of each within the context of construction management.

\section{CONCLUSIONS}

The character of tacit knowledge has implications for recognising the limitations of performance management measures particularly key performance indicators. The objectivist knowledge management perspective that explicit knowledge is taken the main mode of knowledge supports the idea that measurability corresponds with value and usefulness with a notable instance of this being the reform movement in construction. In terms of reviews, policy initiatives and organisations the movement has been and remains an important driver for alterations to improve practice. These changes involve identification of best practice via heavy reliance on measurability. However, the emphasis on measurability results in insufficient recognition of what cannot be measured coupled with excessive stress on the readily measurable and codifiable aspects of performance (Fernie et al. 2006). Tacit knowledge has an essential role in explaining what is best (or conversely substandard) practice and in so doing contributing to its improvement. Explanations of practice which lack the significant context which tacit knowledge provides are likely to be uninformative in some way particularly since this knowledge cannot be replaced by explicit knowledge. Given that by its very nature tacit knowledge is resistant to measurement much more attention should be paid to the connection between what can be measured and what cannot. This should be coupled with consideration about how to best to handle the latter and recognition that not all aspects of performance are measurable (Fernie et al. 2006). The importance of tacit knowledge can also be seen in the usage of the increasingly important performance management tool of building information modelling and management systems. These systems effectively employment explicit knowledge to track and manage project information but they cannot capture the tacit knowledge which is also a crucial part of successful project delivery. For example, Jaradat et al. (2013) found that some professionals objected to certain ways in which computer systems were used such as the requirement to spend time updating files instead of just carrying on and dealing with problems as they arose. Here the resistance is to what is perceived as unnecessary explicit knowledge at the expense of problem solution best dealt with by tacit knowledge.

Improving performance requires appreciating the limitations of objectivist and practice based knowledge management within the context of construction projects. This includes understanding the extent to which tacit knowledge constrains the identification and dissemination of best practice and that as a consequence the latter should be regarded as a family resemblance concept. Taking best practice in this way enables many kinds of best practice which combine performance management measures with approaches like sensemaking in varying combinations.

\section{REFERENCES}

Anumba, C, Egbu, C and Carrillo, P (2005) “Knowledge management in construction”. Oxford: Blackwell.

Baumard, P (1999) “Tacit knowledge in organizations”. London: Sage. 
Boyd, D (2006) Developing a knowledge centric approach to construction education. "Architectural Engineering and Design Management", 2, 149-159.

Burrell G and Morgan G (1979) "Sociological paradigms and organisational analysis". London: Heinemann.

Collins, H (2010) "Tacit and explicit knowledge". Chicago: University of Chicago Press

Cook, S and Brown, J (1999) Bridging epistemologies: the generative dance between organizational knowledge and organizational knowing. "Organization Science", 10(4), 381-400.

Druker, J and White, G (1996) “Managing people in construction”. London: Institute for Personnel and Development.

Egbu, C (2004) Managing knowledge and intellectual capital for improved organisational innovations in the construction industry: an examination of critical success factors. "Engineering, Construction and Architectural Management", 11(5), 301-315.

Egbu, C and Robinson, H (2005) Construction as knowledge based industry, In: C. Anumba, C. Egbu, and P. Carrillo (eds.), "Knowledge Management in Construction". Oxford: Blackwell.

Egan, J (1998) "Re-thinking construction: report of the construction industry task force". London: DETR

Fernie S, Leiringer, R and Thorpe, $\mathrm{T}$ (2006) Rethinking change in construction: a critical perspective. "Building Research and Information", 34(2), 91-103.

Gobet, F (2005) Chunking models of expertise: implications for education. "Applied Cognitive Psychology", 19, 183-204.

Hislop, D (2009) "Knowledge management in organizations: a critical introduction". Oxford: Oxford University Press.

Jaradat S, Whyte, J and Luck, R (2013) Professionalism in digitally mediated project work. "Building Research and Information" 41(1), 51-59.

Kakabadse N, Kakabadse, A and Kouzmin, A (2003) Reviewing the knowledge management literature: towards a taxonomy. "Journal of Knowledge Management" 7(4), 75-91.

Latham, M (1994) "Constructing the team: joint review of procurement and contractual arrangements in the United Kingdom construction industry". London: HMSO.

Lave, J and Wenger, E (1991) "Situated learning: legitimate peripheral participation". Cambridge: Cambridge University Press.

Mingers, J (2008) Management knowledge and knowledge management: realism and forms of truth. "Knowledge Management Research and Practice", 6(1), 62-76.

Nonaka, I and Takeuchi, H (1995) “The knowledge-creating company”. Oxford: Oxford University Press.

Nonaka, I, Toyama, R and Konno, N (2000) SECI, ba and leadership: a united model of dynamic knowledge creation. "Long Range Planning", 33, 5-34.

Polanyi, M (1958) “Personal knowledge: towards a post-critical philosophy”. London: Routledge.

Polanyi, M (1966) “The tacit dimension”. Doubleday: New York.

Ryle, G (1946) Knowing how and knowing that. "Proceedings of the Aristotelian Society", 56, 212-225.

Ryle, G. (1949) “The concept of mind”. London: Hutchinson. 
Schultze, U. and Stabell, C. (2004), Knowing what you don't know? Discourses and contradictions in knowledge management research. "Journal of Management Studies", 41(4), 549-573.

Sheehan, T, Poole, D, Lyttle, I and Egbu, C (2005) Strategies and business case for knowledge management. In C. Anumba, C. Egbu, and P. Carrillo (eds.) "Knowledge Management in Construction" Oxford: Blackwell.

Tan H, Anumba, C, Carrillo, P, Bouchlaghem, D, Kamara, J and Udeaja, C (2010) "Capture and reuse of project knowledge in construction”. Chichester: Wiley Blackwell.

Tsoukas, H (2003). Do we really understand tacit knowledge? In: Easterby-Smith M. and Lyles M. (eds.) "Handbook of Organizational Learning and Knowledge Management". Oxford: Blackwell.

Weick, K (2001) “Making sense of the organization”. Oxford: Blackwell.

Weick, K (1995) “Sensemaking in organisations". London: Sage.

Winch C. (2009) Ryle on knowing how and the possibility of vocational education. "Journal of Applied Philosophy" 26(1), 88-101.

Winch, C (2010) “Dimensions of expertise”. London: Continuum.

Wittgenstein, L (2009) “Philosophical investigations”. Oxford: Blackwell.

Wolstenholme, A (2009) "Never waste a good crisis". London: Constructing Excellence. 